\title{
Features of prosecutorial inspections of criminal fires (by the example of Kuzbass) as markers of sustainable development of mining region
}

\author{
Roman Drapezo ${ }^{1}$, and Viktor Kalashnikov ${ }^{1}$ \\ ${ }^{1}$ Kemerovo State University, 650000, 6 Krasnaya st., Kemerovo, Russian Federation
}

\begin{abstract}
In this article, the authors consider the issues of using coal as one of the main sources of thermal energy when hiding criminal corpses by burning. It has been established that it is impossible to reproduce the conditions of a crematorium under domestic conditions, and therefore, in order to destroy a corpse, a criminal needs access to a heat source on an industrial scale. Most often, criminals use boiler and stoker stoves to hide the corpse, or destroy the corpse in storage facilities where coal is stored. In the course of investigating criminal cases about these crimes, investigators must find out how the criminal was able to get access to the source of energy - coal, in cases where the coal does not belong to him on the basis of ownership. Meanwhile, the study of criminal cases showed that the duties under consideration are not fulfilled by investigators properly or are not performed at all. The article touches upon the issues of prosecutor's supervision over the investigation of this category of cases, and measures that the prosecutor could take to activate the investigation bodies and other officials in order to counteract the use of coal in criminal acts.
\end{abstract}

\section{Introduction}

In the 21 st century, Russia, like all humanity, has faced with management, demographic, raw materials, environmental, and other global crises. The theory of social development optimization explains their variety, the lag of science behind the practical needs of a person, since its predominant differentiation is less and less balanced by integrative approaches. Therefore, the frequency of natural disasters, wars, man-made disasters and other dangers that have become usual in our life will increase until a person moves from a culture of reaction to a culture of their prevention, which is not only more humane, but also cheaper for the society.

It was found that with smooth development of society, response changes in structures (resistance) develop linearly. In other words, society reacts quite predictably to moderate, even multiple loads. A margin of safety or resistance keeps society from unpredictable development trajectories (sustainable development). However, with their multiple increase (of any kind of external influence), the structure reacts with an abrupt response - "explosion". According to the "all or nothing" principle, when a living (and as scientists from other scientific fields have shown a technical) system does not react to multiple impacts of non-critical amplitude, and vice versa, when the impacts reach their critical mass, the system responds its greatest possible reaction. This is the fundamental meaning, universal for living and technical 
systems, when the internal reserve preserves the structural and functional diversity of the system, and under extreme loads leads to a chaotic state.

It is quite natural that these signs of sustainable development have found their direct reflection in the strategic national priorities of the state. Entered into force by the Decree of the President of the Russian Federation on December 31, 2015 No. 683 "Strategy of national security of the Russian Federation" [1] really includes such priority criteria as: criminological security, security in emergency situations, social security, demographic safety, etc. However, we propose a different approach to assessing sustainable development, using not direct measured well-being indicators of mining region, but the opposite criteria of ill-being. From the author's point of view, these can be markers of death of people, including criminal fires and murders associated with fire, where coal was used as the main combustible substance by criminals, as a completely accessible source of fire in the coal region (for example, Kuzbass).

If we proceed from the official statistics for the Russian Federation and the Kemerovo region $[2,3]$, then the leading positions are indeed occupied by criminal fires. It should be noted that we are interested in criminal fires and murders associated with fire not only as indicators of statistics that are reflected in the reports, but their internal nature, which depends little on the social-and-economic well-being of mining region.

It is known that in domestic conditions it is difficult to burn a human body to an ash residue, since the process requires a significant amount of time and a high combustion temperature $[4,5]$. Nevertheless, in some foreign literature, we find in vivo model experiments, when the bodies of animals and corpses (unclaimed) can be burned to ash matter within 5-6 hours using an open fire with a sufficient flow of oxygen $[6,7]$, including the use of coal as a combustible substance.

In this regard, the question of finding out by the investigator, in the proceedings of which there is a criminal case of murder with destruction or attempted destruction of the victim's corpse by incineration, the specific method of burning the body, the materials used for this, access to stoves with a high temperature, becomes relevant. In the process of clarifying the circumstances under consideration, it is possible to identify the illegal activities of other persons who assisted in the destruction of the traces of crime, or the negligence of officials and other responsible persons who facilitated the concealment of the traces of crime, for example, the owners of boiler houses, warehouse facilities for storing coal. Timely submission in accordance with Art. 158 of the Code of Criminal Procedure of the Russian Federation, aimed at providing and protecting stokers, boiler rooms, storage facilities that ensure the impossibility of access to them by unauthorized persons, will create additional difficulties for criminals in complete destruction of corpses.

Accordingly, when exercising supervision over the procedural activities of the preliminary investigation bodies, the supervising prosecutors should pay attention to the fulfillment by the investigators in whose proceedings the cases are, the requirements provided in Part 2 of Art. 73 and Art. 158 of the Criminal Procedure Code of the Russian Federation, including by introducing acts of the prosecutor's response, aimed at forcing the preliminary investigation bodies to clarify the circumstances of the destruction of the victims' corpses.

We set a goal to consider the completeness of measures taken by the bodies of preliminary investigation and the prosecutor's office aimed at clarifying the conditions conducive to the destruction of criminal corpses by burning by the example Kemerovo city and the Kemerovo region. The following tasks were set: 1) to establish methods and places of corpses of victims' destruction by burning; 2) reveal their essence; 3) propose possible solutions aimed at the inability or inaccessibility of their use. 


\section{Materials and Methods}

To achieve the above objectives, it was decided to include in the empirical base of the study: 1) materials of criminal cases initiated on the fact of murder associated with fire [8];2) acts of the forensic medical examination of the charred corpses of the Bureau of Forensic Medical Examination of Kemerovo [9]; 3) statistics data from the official websites of the Ministry of Internal Affairs of Russia [2] and the Ministry of Emergencies of Russia [3].

Cluster analysis made it possible to group the data of the empirical base into three groups, depending on the distance between the place of direct murder of the victim and the place where the traces of crime were concealed with the help of fire. At the same time, as a combustible substance, one way or another, criminals used coal directly, or (as our study showed), most often in tandem with other combustible substances (for example, "coal - acetone"; "coal - motor oil", etc.). Three groups were identified: group 1 is characterized by the fact that the distance from the place of murder to the place of burning the corpse of the victim is minimal or it coincides; group 2 - distance on average from 10 to 100 meters and, group 3 - more than 100 meters with a maximum of $2-3 \mathrm{~km}$.

Most likely, the criminals sought to ignite the coal faster, which requires a different, more aggressive combustible. At the same time, coal, as a combustible substance, was used by criminals in overwhelming cases as a means of hiding the traces of crime and, less often, as a murder weapon.

Also, the use of a hired "torch" is considered by us as a private, but significant kind of direct intent. The hiring persons (at the present stage this is done via the Internet) have a direct intent to inflict material harm (setting fire to property, most often a car) or to kill another person. The hired "torch" in this case acts as a means of achieving a criminal goal.

The empirical material of the research was subjected to statistical processing. Methods of descriptive statistics, cluster analysis, graphical and correlation analysis methods were applied. The reliability of the results ( $r$ ) was assessed at a prediction significance level of $r$ $<0.05$. The diagrams were built using the Excel 2010 program, the statistical analysis was carried out using the Statistica 13 software.

\section{Results and Discussions}

According to official statistics for 2020, 439,100 cases of fires were recorded in the Russian Federation, in which more than 8 thousand people died, and about 10 thousand people were injured. According to the same statistics, the third / fourth place is consistently held by arson and unidentified causes of fires (more than 14 thousand). Intentional destruction or damage to property by arson was registered over 6 thousand, while only 2011 crimes were solved. In more than $80 \%$ of cases, there is a refusal to initiate criminal cases. Accordingly, the true causes of fires have not been identified. And the point here is not only the latency of crimes (meaning murders associated with fire) and the lack of a corresponding indicator in the statistical reporting, but in their concealment, including murders disguised as careless handling of fire. Such cases are described not only in domestic literature, but also in foreign sources [10]. This once again testifies to the inadequacy of the measures taken by the preliminary investigation bodies and the prosecutor's office in the field of clarifying the conditions assisting the destruction of criminal corpses by burning. 


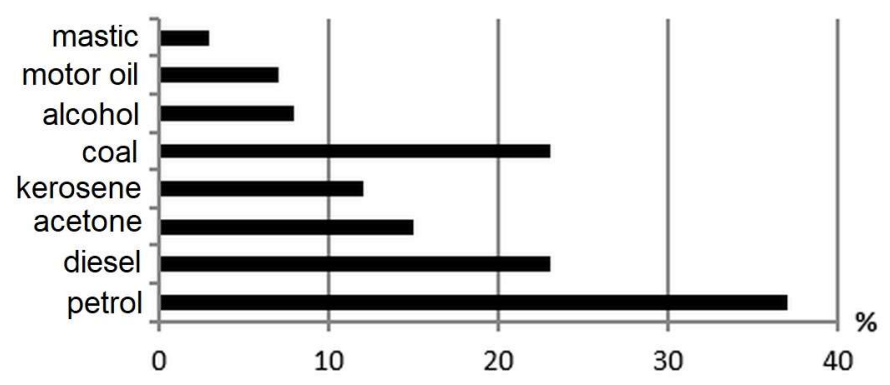

Fig. 1. The frequency of coal use as a combustible substance among other substances.

In fig. 1, we presented the distribution profile of the use of coal as a combustible substance among other substances. It can be seen that the frequency of coal use distracts the general profile.

In this case, the sum of frequencies goes beyond $100 \%$. This is explained by the fact that criminals most often use coal in tandem with another combustible substance, for example (in decreasing order of importance): gasoline, diesel fuel, acetone, kerosene, alcohol, motor oil, sunflower oil, mastic, cologne, etc. It is interesting to note that coal (in a smoldering form) was also used by criminals as a source of ignition, along with matches, a lighter, an unextinguished cigarette, an explosive device, and was also included as fuel in home-made devices that simulate spontaneous combustion. The danger lies in the fact that the criminals used burning or already smoldering coals from working stoves, boilers, stoker, etc.

According to our research, most often criminal burning of corpses was observed in stoves / stoker / boiler rooms and in private houses (see Fig. 2). Also, criminal burnings were recorded in storage facilities where coal is stored. Least of all was noted in the forest, forest park zone, and this is explained by the problematic transportation of coal to the place of destruction of the traces of crime. Criminal burnings were also noted in cars outside the city zone near abandoned buildings, where coal was delivered in advance by criminals.

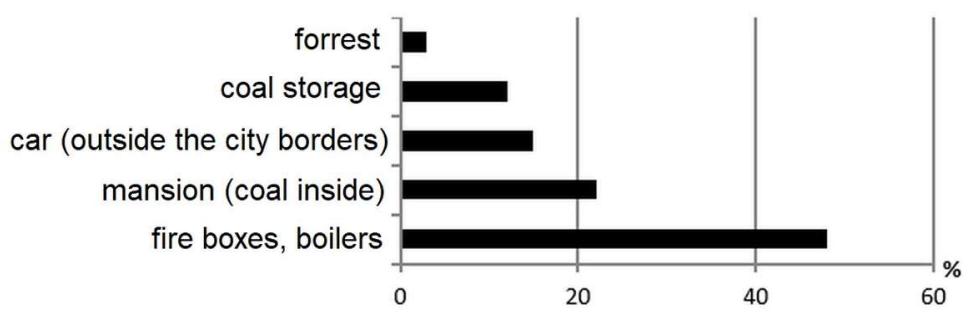

Fig. 2. Frequency distribution of places of murders associated with fire, where coal was used as a combustible substance.

We have found that the use of coal for criminal burning correlates with the personality of the criminal. Here are some correlations as an example:

- a crime is committed in a group or alone, but by hiring a "torch" via the Internet $(84.4 \%$ of cases);

- the criminals are familiar with the victim ( $72 \%$ of cases);

- criminals are local residents $(76.6 \%$ of cases);

- the victims are relatives who beat cohabitants, businessmen ( $73.2 \%$ of cases);

- crimes are committed by persons aged $25-28$ years ( $88.1 \%$ of cases). 


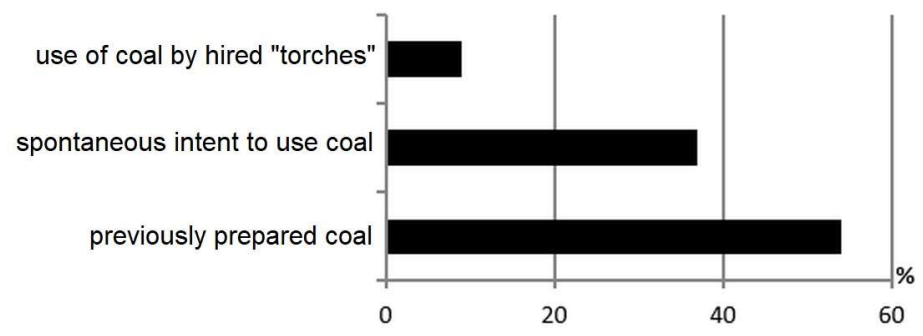

Fig. 3. The frequency of intention to use coal as a combustible substance in a criminal.

Fig. 3 reflects the occurrence frequency of coal use as a combustible substance by a criminal during criminal combustion. It can be seen that most often the coal was prepared in advance by the subjects of the crime; in less than $40 \%$ of cases, there is a spontaneous emergence of intent to use coal as a means of hiding the traces of a crime. It was found that in about $10 \%$ of cases, individuals (customers) hired torches through the darknet. It is important to note that the hired "torches" searched in advance for the abandoned premises where the coal was delivered. Further, the corpse of the victim was transported to the indicated premises for further concealment of the traces of murder. Sometimes, in such unowned warehouses, coal is temporarily stored by "black diggers" for its further illegal sale [11, 12].

Table 1. Frequency of occurrence of the victim's corpse movement to the place of its burning, depending on the groups identified by the cluster analysis.

\begin{tabular}{|c|c|c|c|}
\hline & \multicolumn{3}{|c|}{$\begin{array}{c}\text { For the purpose of burning, the corpse of the victim } \\
\text { was moved within (\% of the cases studied) }\end{array}$} \\
\hline Distance & $\begin{array}{c}\text { Group 1 } \\
(0-2 \mathrm{~m})\end{array}$ & $\begin{array}{c}\text { Group 2 } \\
(10-100 \mathrm{~m})\end{array}$ & $\begin{array}{c}\text { Group 3 } \\
(2-3 \mathrm{~km})\end{array}$ \\
\hline $\begin{array}{c}\text { Corpse } \\
\text { movement }\end{array}$ & 9.3 & 67.7 & 23.0 \\
\hline
\end{tabular}

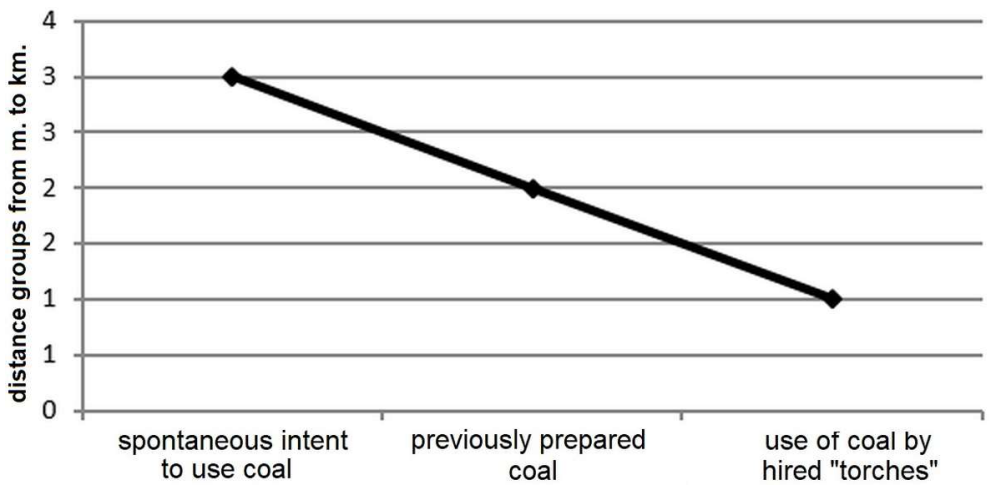

Fig. 4. Correlation dependence $(r=-0.98$, at $\mathrm{p}<0.05)$ between the intention of the criminal to use coal as a combustible substance and the distance from the place of direct murder to the place where the traces of murder were hidden by fire.

We have recorded an interesting correlation dependence (see Table 1. and Fig. 4) between the intent of the suspected persons and the movement of the victim's body into the zone of 
direct criminal burning. In fig. 4 it can be seen that if the hired "torch" uses coal as a combustible substance, then the movement of the body practically does not occur. There are at least two explanations for this: 1) "torches" prepare in advance the place and means of destroying traces of the client's criminal activity; 2) "torches" tend not to leave traces of their physical presence at the scene. And, on the contrary, with a spontaneously arising intent, criminals, in order to hide the traces of a murder, due to an unplanned crime, are ready to move the body to the place of its direct destruction by fire over long distances.

This, in turn, leaves a significant amount of traces of criminal activity. With a sudden intent, the criminals try to cover the corpse of the victim with burning coals from above. The correlations show that these are persons who are closely acquainted with the victims, possibly in a family relationship, with such motives of the crime as revenge, jealousy, greed. They also search for ways to completely destroy the human body via the Internet. This gives us reason to recommend investigators to study in detail the computer browser history and other electronic media of information from persons suspected of crimes of the studied category.

The study of criminal cases in the proceedings of the investigative bodies on murder cases, in which the traces of the crime were destroyed by burning the victim's body, showed that the investigators did not fully implement their powers to make submissions provided in Art. 158 of the Criminal Procedure Code of the Russian Federation. At the same time, as the study showed, the use of boilers and stokers for burning corpse prevails over other methods of destroying traces. Meanwhile, the adductions of investigator, aimed at the real elimination of the real causes and conditions that contributed to the commission of crimes, have not been encountered in any criminal case. Formal adductions containing generalized, non-specific requirements were contained in single cases. Naturally, the answers of the responsible officials were of a similar formal nature and did not contain information about the real elimination of the reasons and conditions that facilitated the criminal's access to the coal storage site or the firebox of stoker.

Of course, the immediate subject of proof in a criminal case of murder does not include circumstances related to the penetration in boiler rooms and coal warehouses, including breaking locking devices or agreements with employees of these enterprises. At the same time, failure to comply with the requirements of the law on establishing the reasons and conditions that facilitated the commission of a crime, and taking measures to eliminate them, allows the offender to count on the possibility of hiding the corpse both before the murder is committed and due to sudden intentions. At the same time, we do not take into account the cases when coal purchased in advance specially for these purposes, or coal owned by the criminal on the right of ownership for heating purposes, is used to burn a corpse. However, from our point of view, investigators should also react to those facts when the victim's body was burned in a forest or in an open area, and coal stolen from the territories adjacent to boiler houses or from storage facilities was used for burning. The cases under consideration are evidence of insufficient protection or its absence of the indicated territories and premises, which can be interpreted as conditions conducive to the concealment of a crime.

The study of criminal cases showed that the supervising prosecutors did not consider the lack of activity of the investigator in clarifying the issues that contributed to the commission of crimes, a violation of the criminal procedure legislation, and did not focus their attention on the need to establish the circumstances under consideration. So, in the acts of the prosecutor's response, introduced in the studied criminal cases, there were no references to such violations as the failure of the investigator to fulfill his duties to take measures to eliminate the causes and conditions that contributed to the commission of crimes. There was no reaction from prosecutors to formal adductions of investigators and answers to them.

The current departmental regulations governing the implementation of prosecutorial supervision over the procedural activities of the preliminary investigation bodies do not attrib- 
ute these shortcomings to the grounds for the return of the criminal case for additional investigation, and therefore, we believe that the circumstances should be clarified earlier, during the supervision of the investigation, in the study of materials justifying the accusation, or in other cases. Forcing by acts of the prosecutor's response to the investigator to perform his immediate duties, the prosecutor can achieve the adoption of effective measures to provide security or observation equipment, alarm in storage facilities and areas intended for coal storage. In addition, regular inspections by responsible officials of boilers and stokers, including at night, will help to improve the discipline of employees of these enterprises, prevent disruption of heating work in winter season, and will also significantly reduce the possibility of using boiler stoves in criminal purposes. The impossibility of using closed premises to destroy the traces of a crime will either force the criminals to realize their criminal intentions in open accessible areas, which can attract the attention of outsiders, or completely force the person who committed the crime to abandon the purpose of burning the corpse. This, in turn, will contribute to solving the crime.

\section{Conclusion}

Based on the foregoing, we made the following conclusions.

1. In criminal cases of murders involving the burning of a corpse, coal as a source of thermal energy aimed at destroying traces of a crime was used in more than $20 \%$ of cases (the second most popular among combustible materials).

2. In the overwhelming majority of cases, criminals used stokers, stoves, and boiler houses using coal as fuel to burn the victim's corpse. In second place are the warehouses for coal storage.

3. Coal preparation (selection of a place to destroy traces of a crime) prevails over spontaneous decisions about the burning of a corpse. In this case, the crime, as a rule, is committed within $2 \mathrm{~km}$ from the place of destruction of the corpse.

4. In the course of the investigation of criminal cases, investigators passively exercise their powers aimed at eliminating the causes and conditions that contribute to the commission of crimes or facilitate its commission.

5. Failure by the investigator who is in charge of the criminal case and the responsible officials to take appropriate measures to eliminate the causes and conditions that contribute to the commission of crimes are not considered by prosecutors as shortcomings in the investigation, in connection with which the latter do not introduce acts of prosecutorial response.

6. Timely coercion of investigators by prosecutors to properly perform their duties in terms of eliminating the causes and conditions for committing crimes, can have a significant impact on the possibility of secret destruction of the victim's corpse by burning with coal.

\section{References}

1. Decree of the President of the Russian Federation of 31.12.2015 No. 683 "On the Strategy of National Security of the Russian Federation". URL: http://www.pravo.gov.ru

2. The official Internet portal of the Ministry of Internal Affairs of Russia. URL: http://mvd.ru

3. The official Internet portal of the EMERCOM of Russia. URL: http://www.mchs.gov.ru

4. O. Prokop, G. Radam, Atlas der gerichtlichen Medizin (Verlag Volk und Gesundheit, Berlin, 1987)

5. J.D. DeHaan, Kirks fire investigation (Simon\&Schuster Company, New Jersey, 2007)

6. M. Efford, The Arbutus Review, 7(1), 20-37 (2016) DOI: 10.18357/tar71201616054. 
7. M.P.M. Marques, D. Goncalves, A.P. Mamede, T. Coutinho, E. Cunha, W. Kockelmann, S.F. Parker, L.A.E. Batista de Carvalho, Sci. Rep. 14;11(1), 1361 (2021) doi: 10.1038/s41598-020-80462-3

8. Archive of criminal cases of the Kemerovo Regional Court from 1989 to 2020 (KRC, Kemerovo, 2020)

9. Archive of the Bureau of Forensic Medical Examination of Kemerovo from 2005 to 2020 (KRC, Kemerovo, 2020)

10. A. Lysova, European Journal of Criminology, 1, 1-2. (2018)

11. V.Shelestukov, R. Drapezo, E3S Web Conf. 105, 02016 (2019)

12. V. Shelestukov, R. Drapezo, E3S Web Conf. 174, 02029 (2020) 